Federal Reserve Bank of Minneapolis

Research Department

\title{
The Effects of Government Purchases on Employment and Hours
}

\author{
R. Anton Braun and Ellen R. McGrattan*
}

Working Paper 519

October 1993

*Braun, Federal Reserve Bank of Minneapolis and University of Virginia; McGrattan, Federal Reserve Bank of Minneapolis. We thank participants at the 1993 NBER summer institute for their comments. The second author thanks the NSF and the Minnesota Supercomputer Institute for their support. The views expressed herein are those of the authors and not necessarily those of the Federal Reserve Bank of Minneapolis or the Federal Reserve System. 


\section{Introduction}

Two notable features of the U.S. data during World War II are the large increases in civilian employment and average weekly hours. During the first several years of the war, the unemployment rate fell to 1 percent. Once the reserve of unemployed was at a minimum, many students, retirees, and women engaged in housework entered the labor force and hours per worker increased. In 1943, the midpoint of the war, the fraction of civilians employed had risen 12 percent above its 1939 level. Average weekly hours in 1943 had risen 19 percent above its 1939 level. In the postwar period, variations in both hours per worker and civilian employment are also evident. The fraction employed has displayed annual percent deviations of about 2 percent, which is approximately 60 percent of the variation in total hours of work. The remainder is due to changes in hours per worker.

In this paper, we use the wartime and postwar experiences of the U.S. to quantify the effects of government purchases on changes in employment and hours. We develop a model and derive its predictions for the two labor inputs. We adopt the technology of Kydland and Prescott [1991] who assume that the number of hours that a plant can operate and the number of employees per plant are choice variables. All workers are assumed to work the same shift. Thus, the number of hours worked per employee is equal to the number of hours that the plant operates. One important difference between the framework of Kydland and Prescott [1991] and the model developed in this paper is our assumption about preferences. We assume that the disutility people experience when entering the workforce differs across individuals. Heterogeneous costs are intended to capture differences between such groups as single men and married women with children. For the function that we choose, the aggregate costs are increasing in the fraction employed. Therefore, in times of large fiscal shocks (e.g., war) both employment and hours per worker are predicted to rise.

In addition to fiscal shocks, we assume that there are shocks to the production technology. For World War II, technology shocks are dominated by fiscal shocks. During the postwar, however, they play an important role for aggregate fluctuations. Cho and Cooley [1992] and Kydland and Prescott [1991] have found, however, that it is difficult to account

for the large movements in employment and hours if technology shocks are the only source of fluctuations. Cho and Cooley [1992] estimate that technology shocks account for a little over one-half of the variation observed in the postwar data. Similar estimates are found 
by Kydland and Prescott [1991].

We estimate the parameters of our model using annual U.S. data and a two-step estimation procedure. First, we estimate a law of motion for military employment by applying the maximum-likelihood procedure outlined in Hamilton [1989]. In the second step, we condition on the estimated process for military employment and estimate the remaining parameters using the simulated method of moments procedure of Lee and Ingram [1989]. We use the parameter estimates to make predictions about the response of hours of work and employment to fiscal shocks. We find that fiscal shocks are an important source of variation in hours per worker and per-capita employment in both wartime and the postwar period. The model accounts for the large movement in hours per worker and per-capita employment observed during World War II. The responses of output and its components are also in good agreement with the data. For the postwar, we find that the amplitude of fluctuations in hours and employment for the model is similar to that of the data.

In Section 2, we describe the model and equilibrium concept that we use. In Section 3 , we characterize the equilibrium for different assumptions about preferences and technologies. Section 4 lays out the estimation procedure and reports the estimation results. In Section 5, we compare simulations from the model to U.S. data between 1941 and 1985.

\section{The Model}

Our model economy is inhabited by a large number of ex-ante identical agents with preferences

$$
E \sum_{t=0}^{\infty} \beta^{t}\left\{U\left(c_{t}, \ell_{t}\right)-\eta_{t} \chi\left(h_{t}>0\right)\right\}, \quad U(c, \ell)=\frac{\left(c^{\gamma} \ell^{1-\gamma}\right)^{1-\omega}-1}{1-\omega}, 0 \leq \beta, \gamma \leq 1, \omega>0
$$

where $c_{t}$ is consumption at date $t, \ell_{t}$ is leisure at date $t, h_{t}=1-\ell_{t}$ is the number of hours spent working at date $t, \eta_{t}$ is a measure of the disutility of entering the workforce in date $t, \chi$ is an indicator function, and $E$ is the expectation operator which is conditioned on the initial state vector. Each period, agents receive a draw of $\eta$, which is identically and independently distributed over time and individuals. ${ }^{1}$

\footnotetext{
1 We could also assume that agents' types are determined at date 0 and fixed through time. Assuming
} 
With the exception of the term $\eta_{t} \chi\left(h_{t}>0\right)$, the choice of preferences is standard. The variable $\eta$ is intended to capture costs associated with employment. For example, the value of $\eta$ is high for women with young children who would prefer homework to work in the market sector. During the World War II, the government tried to assess these costs of employment. In the March 1943 issue, the Survey of Current Business reported results from a Census survey that attempted to characterize nonworkers and their potential as recruits for the labor force. "According to Census estimates, there appeared to be in November 1942 a volunteer United States labor reserve of 5,000,000 persons 14 years old and older. It was composed of people willing and able to take full-time jobs under certain conditions. [T] his volunteer reserve is composed largely of women, most of whom are engaged in home housework. Of these, 83 percent are married and 40 percent are responsible for the care of children - largely children under 10 years of age. These family responsibilities obviously hinder to some extent their freedom of work." (Survey, March 1943, p. 4.) ${ }^{2}$

We assume that an agent that works $h_{t}$ hours with $k_{t}$ units of private capital and $k_{g, t}$ units of public capital produces a homogeneous good, $y_{t}$, with the following production technology:

$$
y_{t}=z_{t}\left\{k_{t}+k_{g, t}\right\}^{\theta} h_{t},
$$

where $z_{t}$ is a shock to technology in period $t$. Note that this technology exhibits increasing returns to scale. Below, we explain how the commodity space can be defined so as to avoid problems with computing equilibria.

In specifying the production technology of Eq. (2), we assume that private and public capital are perfect substitutes. If they are not perfect substitutes, then the marginal returns of the two capital stocks differ. In peacetime, when $k_{g, t}$ is low, its marginal return is high and there are presumably large gains to further investment. However, we observe most government investment in productive capacity during wartime. Private and public capital are assumed to depreciate at the same rate,

$$
\begin{aligned}
k_{t+1} & =(1-\delta) k_{t}+i_{t} \\
k_{g, t+1} & =(1-\delta) k_{g, t}+i_{g, t}
\end{aligned}
$$

the necessary asset markets are available, the two specifications are equivalent.

2 The term volunteer does not mean work without pay. The volunteer reserve were those willing to enter the labor force under certain conditions. 
where $i_{t}$ is private investment at $t, i_{g, t}$ is government investment at $t$, and $0 \leq \delta \leq 1$ is the rate of depreciation. Government investment is exogenously determined and is taken to be a function of the state $s_{t}$ in period $t$. The variable $s$ is a $l$-state Markov chain with states that depend on the level of fiscal spending and whether or not the country is at war. For example, to capture high government investment in periods of war and low government investment in periods of peace, we can set $l=2$, and $i_{g, t}=i_{g}\left(s_{t}\right)$ high for $s_{t}=1$ and low for $s_{i}=2$. In this example, the value of $s$ indicates whether or not the country is in war or in peace.

As in Kydland and Prescott [1991], we allow for costs to moving people between the household and market sectors. In particular, we assume that an individual incurs a resource cost of $m_{t}$ in date $t$ if $h_{t}=0$ and $h_{t-1}>0$ or $h_{t}>0$ and $h_{t-1}=0$. Thus, output is used for either consumption, investment, or moving between sectors. If the period length is short, the moving costs can be interpreted as costs to commuting. For longer periods, these costs can be interpreted as hiring and firing costs.

The technology shock in equation (2) is assumed to follow an autoregressive process,

$$
\log \left(z_{t}\right)=\rho \log \left(z_{t-1}\right)+\epsilon_{t}
$$

where $\epsilon_{t}$ is a serially uncorrelated error term which is normally distributed with mean zero and variance $\sigma_{\epsilon}^{2}$.

Note that the production technology in equation (2) exhibits increasing returns to scale. However, if we assume capital is specific to a household and that agents buy and sell lotteries over bundles of goods, hours, and capital, as in Prescott and Townsend [1984], then we can convexify the commodity space. Suppose that agents enter into contracts which specify the number of hours to work and the number of units of capital to provide. In return for hours and capital, the agents receive consumption goods. Let $x(A)$ denote the measure of agents consuming $c$, working $h$, and using $k$, for $(c, h, k) \in A$. Then, aggregate output is given by

$$
z \int h\left(k+k_{g}\right)^{\theta} d x
$$

which exhibits constant returns to scale if the inputs are the measures, $x{ }^{3}$ To compute the equilibrium decisions, we can exploit the fact that the competitive equilibrium is Pareto

${ }^{3}$ If the set of possible $(h, k)$ pairs is discrete, then output is given by $z \sum_{h} \sum_{k} h\left(k+k_{g}\right)^{\theta} x_{h, k}$ where 
optimal and solve the social planner's problem. The current return for the planner is given by

$$
R\left(I, K, L, N, k_{g}, z, s\right)=\max _{x}(1-a(s))\left\{\int U(c, 1-h) d x-p(N)\right\}
$$

where the maximization is subject to

$$
\begin{aligned}
& \int c d x+I+m(L, N)+c_{g}(z, s)+i_{g}(s) \leq z \int h\left(k+k_{g}\right)^{\theta} d x \\
& \int k d x \leq K \\
& \int d x=1 \\
& x(\{h>0\})=N .
\end{aligned}
$$

The capital letters, $K, I, L$, and $N$, are used to denote population means of the capital stock, investment, the fraction employed last period, and the fraction employed currently, respectively. The function $a$ is the fraction of individuals in the army and depends on the state, $s$. We have ignored the utility of those in the army since it depends only on exogenously determined variables. The function $p$ is the aggregate cost function, i.e.,

$$
p(N)=\int_{0}^{N} q(j) d j
$$

where $q(j)$ is a monotonically increasing function which represents is the cost to individual $j$ of entering the workforce. We assume that individuals with the lowest values of $\eta(=q(j))$ are employed first. Because $\eta$ in (1) is independently and identically distributed, the group of employed individuals may not be the same through time. However, since the aggregate consequences are the same for this problem and one with types determined at date 0 , the assumption on $\eta$ is somewhat innocuous.

The first constraint (below Eq. (7)) for the planner is the resource constraint. Output is consumed by households $(c)$, consumed by the government $\left(c_{g}\right)$, invested privately $(i)$, invested publicly $\left(i_{g}\right)$, or used in moving people between sectors $(m)$. We assume that government investment and government consumption depend on the state $s$. We have also included the technology shock as an argument of government consumption. This

$x_{h, k}$ denotes the number of individuals who work $h$ hours and use $k$ units of the capital stock. Scaling all of the terms $x_{h, k}$ by $\kappa$ yields $\kappa\left(z \sum_{h} \sum_{k} h\left(k+k_{g}\right)^{\theta} x_{h, k}\right.$. 
specification allows us to capture peacetime fluctuations in government spending. The function $m$ is the aggregate moving cost function, i.e.,

$$
m(L, N)=\int_{0}^{|N-L|} r(j) d j
$$

where $r(j)$ is the cost of moving individual $j$ between sectors. The second constraint of the planner's problem ensures that the levels of capital chosen by the private sector are less than the stock available. The fourth constraint states that the number employed is equal to the number of individuals who work a positive number of hours.

Given the return function in equation (7), the value function for the planner is given by

$$
v\left(K, k_{g}, L, z, s\right)=\max _{I, N}\left\{R\left(I, K, L, N, k_{g}, z, s\right)+\beta \sum_{s^{\prime}} \pi_{s^{\prime} \mid s} \int v\left(K^{\prime}, k_{g}^{\prime}, L^{\prime}, z^{\prime}, s^{\prime}\right) g(\epsilon) d \epsilon\right\}
$$

subject to

$$
\begin{aligned}
K^{\prime} & =(1-\delta) K+I, \\
L^{\prime} & =N,
\end{aligned}
$$

equations (4) and (5), and the specification for the Markov chain for $s$. The function $g$ in (9) is the normal density. The function $\pi_{s^{\prime} \mid s}$ in (9) is the transition function for the Markov chain.

Hornstein and Prescott [1993] show that for the class of problems that includes ours, the equilibrium consumption vector places mass on only two points. The first has zero hours and zero units of capital, and the agent receives $c_{0}$ consumption goods. The second has a positive value for hours and capital and the agent receives $c_{1}$ consumption goods. Thus, we need not search over all possible lotteries. We can restate the planner's problem as follows:

$$
\max _{\left\{c_{1, t}, c_{0, t}, i_{t}, h_{t}, n_{t}\right\}} E \sum_{t=0}^{\infty} \beta^{t}\left\{n_{t} U\left(c_{1, t}, 1-h_{t}\right)+\left(1-n_{t}\right) U\left(c_{0, t}, 1\right)-p\left(n_{t}\right)\right\}\left(1-a_{t}\right)
$$

subject to

$$
n_{t} c_{1, t}+\left(1-n_{t}\right) c_{0, t}+i_{t}+i_{g, t}+c_{g, t} \leq z_{t}\left(\frac{k_{t}+k_{g, t}}{n_{t}}\right)^{\theta} h_{t} n_{t}
$$

and equations (3), (4), and (5), where $c_{1}$ is consumption of those working in the private sector, $c_{0}$ is consumption of those not working, $i$ is private investment, $i_{g}$ is government 
investment, $c_{g}$ is government consumption, $k$ is private capital, $k_{g}$ is government capital, $a$ is the fraction of the population in the military, $n$ is the fraction of the population employed in the civilian sector, and $h$ is the number of hours that the plant is operated. The terms of the resource constraint are now expressed as per capita values. Thus, percapita consumption in $t$ is given by $c_{t}=n_{t} c_{1, t}+\left(1-n_{t}\right) c_{0, t}$. The variables $a_{t}$ and $i_{g, t}$ are functions of $s_{t}$ and the variable $c_{g, t}$ is a function of $s_{t}$ and $z_{t}$.

To compute an equilibrium for this economy, we compute the decision functions, namely $c_{1}\left(k_{t}+k_{g, t}, n_{t-1}, z_{t}, s_{t}\right), c_{0}\left(k_{t}+k_{g, t}, n_{t-1}, z_{t}, s_{t}\right), h\left(k_{t}+k_{g, t}, n_{t-1}, z_{t}, s_{t}\right)$, and $n\left(k_{t}+\right.$ $\left.k_{g, t}, n_{t-1}, z_{t}, s_{t}\right)$, that maximize the social welfare function in Eq. (11).

\section{Characterization of Equilibrium}

In this section, we provide a characterization of the model's equilibrium for several specifications of preferences and technology. In doing so, we hope to illustrate how our assumptions affect the simulation results of Section 5 .

We start with the simplest example. Suppose that the resource (i.e., $m\left(n_{t-1}, n_{t}\right)$ and utility costs (i.e., $p\left(n_{t}\right)$ ) associated with changing the fraction of people employed were both zero. In equilibrium, the following conditions must hold at all dates $t$ :

$$
\begin{aligned}
& \frac{\partial U\left(c_{0, t}, 1\right)}{\partial c_{0, t}}=\frac{\partial U\left(c_{1, t}, 1-h_{t}\right)}{\partial c_{1, t}} \\
& n_{t} \frac{\partial U\left(c_{1, t}, 1-h_{t}\right)}{\partial \ell_{t}}=\frac{\partial U\left(c_{1, t}, 1-h_{t}\right)}{\partial c_{1, t}} z_{t}\left(k_{t}+k_{g, t}\right)^{\theta} n_{t}^{1-\theta} \\
& U\left(c_{1, t}, 1-h_{t}\right)-U\left(c_{0, t}, 1\right)=\frac{\partial U\left(c_{1, t}, 1-h_{t}\right)}{\partial c_{1, t}}\left(c_{1, t}-c_{0, t}-(1-\theta) z_{t}\left(k_{t}+k_{g, t}\right)^{\theta} n_{t}^{-\theta} h_{t}\right) .
\end{aligned}
$$

These conditions follow from the optimization problem described in Section 2. The first condition equates the marginal utilities of those working with those who are not working. The second condition equates the ratio of the marginal utility of leisure of the working agent to the marginal benefit of running the plant an extra hour. The third condition equates the change in welfare due to one more person working to the additional output produced by having an additional employee. With some manipulation of these three equations we have the following condition:

$$
-\psi^{-1}\left(1-h_{t}\right) \frac{\left\{\left(1-h_{t}\right)^{\psi}\right\}^{1-\omega}-1}{1-\omega}=(1-\theta) h_{t}, \quad \psi=\frac{1-\gamma}{\gamma(1-\omega)-1} .
$$


Notice that this formula involves only $h_{t}$ and the parameters of the utility and production functions. Therefore, $h_{t}$ must be constant in equilibrium. Furthermore, there are only two fixed points of Eq. (15). $h_{t}=0$ and $0<h_{t}<1$. This follows from the fact that the left hand side of the equation is a concave function that is equal to 0 if $h_{t}=0$, equal to 1 if $h_{t}=1$, and has a derivative equal to 1 at 0 . If $0<\theta<1$, then the right hand side has a slope that is between 0 and 1 . Therefore, the linear function $(1-\theta) h_{t}$ crosses the concave function twice, once at 0 and once at some point in $(0,1)$. We can exclude the $h_{t}=0$ outcome since it is not an optimum. Therefore, to calculate the equilibrium hours decision, we find the positive fixed point of Eq. (15).

With only the extensive margin operating, the model is analogous to Hansen's (1985) indivisible labor economy. Hansen assumes that the utility function has a logarithmic form. In that case, the level of consumption of those working equals the level of consumption of those not working $\left(c_{1 t}=c_{0 t}\right)$. Therefore, the preferences are given by

$$
E \sum_{t} \beta^{t}\left\{\log \left(c_{t}\right)+\frac{1-\gamma}{\gamma} \log (1-\bar{h}) n_{t}\right\}
$$

where $\bar{h}$ is the fixed point of Eq. (15). This is the specification used by Hansen. Furthermore, assuming no government capital, aggregate output is given by $\bar{h} z_{t} k_{t}^{\theta} n_{t}^{1-\theta}$ as in Hansen.

The problem with assuming that all of the variation in total hours is due to changes in employment is the fact that this assumption is at odds with the data. However, if resource or utility costs due to adjusting employment are nontrivial, then an equilibrium will involve variation in both employment and hours per worker. Consider first the case with heterogeneous utilities, $p(N)>0$ for some $N$, and a logarithmic form for $U$. In this case, we replace constraint (14) with

$$
\frac{1-\gamma}{\gamma\left(1-h_{t}\right)}\left\{\left(1-h_{t}\right) \log \left(1-h_{t}\right)+(1-\theta) h_{t}\right\}=p^{\prime}\left(n_{t}\right) .
$$

The left hand side of Eq. (16) is a function of $h_{t}$ and several parameters. For values below the value $\bar{h}$ which is the positive fixed point of Eq. (15), the function on the left hand side of Eq. (16) is negative. For values above $\bar{h}$, the function on the left hand side of Eq. (16) is positive. Suppose that $p(n)$ is chosen to be equal to zero for $n \in[0, \bar{n}]$ and strictly increasing for $n>\bar{n}$. One function satisfying this specification is $p(n)=p_{b}\left\{\left(n-p_{a}\right)^{3}+\left|n-p_{a}\right|^{3}\right\}$ 
for $p_{a} \in[0,1]$ and $p_{b}>0$. In this case, hours as a function of the capital stock $(k)$ is decreasing in $k$ until some level $\vec{k}$ and then it is flat. This follows from equation (16) if we assume that low values of $n_{t}$ occur when the capital stock is high. For $n_{t}<\bar{n}, p^{\prime}\left(n_{t}\right)$ is equal to 0 and $h_{t}=\bar{h}$. For $n_{t}>\bar{n}, p^{\prime}\left(n_{t}\right)>0$ and, therefore $h_{t}>\bar{h}$. Thus, with this specification, we would predict hours to increase if the capital stock fell below a certain level, say because of a war.

For a final example, we consider a case with nonzero moving costs. If $m\left(n_{t-1}, n_{t}\right)>0$ for some values of $n_{t-1}$ and $n_{t}$, then the constraint in (14) must be replaced by

$$
\begin{aligned}
U\left(c_{1, t}, 1-h_{t}\right) & -U\left(c_{0, t}, 1\right)-\frac{\partial U\left(c_{1, t}, 1-h_{t}\right)}{\partial c_{1, t}}\left(c_{1, t}-c_{0, t}-(1-\theta) z_{t}\left(k_{t}+k_{g, t}\right)^{\theta} n_{t}^{-\theta} h_{t}\right) \\
=p^{t}\left(n_{t}\right)+ & \beta E_{t}\left\{\frac{1-a_{t+1}}{1-a_{t}} \cdot \frac{\partial U\left(c_{1, t+1}, 1-h_{t+1}\right)}{\partial c_{1, t+1}} \frac{\partial m\left(n_{t+1}, n_{t}\right)}{\partial n_{t}}\right\} \\
& +\frac{\partial U\left(c_{1, t}, 1-h_{t}\right)}{\partial c_{1, t}} \frac{\partial m\left(n_{t}, n_{t-1}\right)}{\partial n_{t}} .
\end{aligned}
$$

Notice that the right hand side is equal to zero if costs to adjusting employment are zero, e.g., $p\left(n_{t}\right)=0$ and $m\left(n_{t-1}, n_{t}\right)=0$ for all $n_{t}, t \geq 0$. In that case, hours are constant. Otherwise, the model predicts that there will be fluctuations in both hours per worker and employment. Consider, for example, moving costs $m\left(n_{t-1}, n_{t}\right)=\alpha\left(n_{t}-n_{t-1}\right)^{2}$. If $\alpha>0$, then a planner maximizing Eq. (11) would try to smooth employment over time by varying hours as well. For $\alpha$ large, hours per worker rather than the fraction employed would be adjusted in response to fiscal or technological shocks.

\section{Estimation}

In this section, we describe the methods that we use to parameterize the model. The model's parameters are estimated in two steps. First, we fit a markov process to military employment, that captures the effects of wars. Second, we estimate the rest of the parameters using the simulation estimator proposed by Lee and Ingram (1992).

We start with the parameterization of the law of motion for the fiscal policy variables. During the twentieth century, fluctuations in fiscal policy variables have been dominated by the effects of wars. We model this property of the data by assuming that military employment, government investment, and government consumption have a common finite 
state markov component. The markov process is estimated using data on the fraction of the working population employed in the military. ${ }^{4}$

Assume that military employment in time $t$ has the following representation:

$$
a_{t}=s_{t}+u_{t}
$$

where $s_{t}$ takes on $l$ distinct values. Associated with $s_{t}$ is the $l \times l$ transition matrix, $\pi_{s^{\prime} \mid s}$, with element $(i, j)$ given by

$$
\pi_{s^{\prime} \mid s}(i, j)=\operatorname{prob}\left(s_{t+1}=i \mid s_{t}=j\right) .
$$

The term $u_{t}$ is assumed to be independently and identically distributed normal variable with mean zero and variance $\sigma_{u}^{2}$. We also assume that the econometrician can only observe the sum of $s_{t}$ and $u_{t}$ and that $s_{t}$ and $u_{t}$ are independent. Hamilton [1989] describes a procedure for calculating maximum likelihood estimates of $\pi_{s^{\prime} \mid s}$ and $\sigma_{u}^{2}$. In order to evaluate the likelihood function it is necessary to calculate the conditional density for $a_{t}$, i.e.,

$$
f\left(a_{t} \mid \Omega_{t}\right)=\sum_{i=1}^{m} f\left(a_{t}, s_{t}=i \mid \Omega_{t-1}\right)
$$

where $\Omega_{t}=\left(a_{t}, \Omega_{t-1}\right)$ and $s_{0}=1$. Hamilton [1991] describes a generalization of the Kalman filtering algorithm for calculating the conditional densities. Then, the log-likelihood of the data is given by

$$
\sum_{t=1}^{T} \log f\left(a_{t} \mid \Omega_{t-1}\right) .
$$

The maximum likelihood estimates for a 4-state representation of military employment are presented in the upper panel of Table 1. These estimates use annual data running from 1900 to 1985 . Using these estimates we can calculate the smoothed probabilities

$$
\operatorname{prob}\left(s_{t}=i \mid \Omega_{T}\right), \quad i=1, \ldots, T .
$$

Figure 1 contains a plot of the data for military expenditures and the smoothed probabilities multiplied by their conditional means. From this plot we see that the estimates

\footnotetext{
4 The data sources are described in the appendix.
} 
predict the wartime peaks for World War I, World War II and the Korean war. On the other hand, this statistical model has more difficulty predicting the magnitude or duration of the Vietnam war and the subsequent decline in military employment after 1970.

The remaining parameters are estimated using the simulated method of moments estimator proposed by Lee and Ingram (1992). This estimator minimizes a quadratic form of discrepancies between a set of simulated moments and their analogues in the data. Let $\phi$ be an $l \times 1$ vector of parameters, $\left\{X_{t}, t=1,2, \ldots, T\right\}$ be the observations where $X_{t}$ is $k \times 1$, and let $\left\{\left(Y_{j}(\phi)\right), j=1,2, \ldots, N\right\}$ be an $k \times 1$ vector of simulated time series. ${ }^{5}$ Denote the $r \times 1$ vector of statistics that is calculated as follows:

$$
Q_{T}(X)=\frac{1}{T} \sum_{t=1}^{T} q\left(X_{t}\right) .
$$

Similarly, denote the $r \times 1$ vector of simulated statistics as

$$
Q_{N}(Y(\phi))=\frac{1}{N} \sum_{j=1}^{N} q\left(Y_{j}(\phi)\right) .
$$

The simulated method of moments estimator proposed by Lec and Ingram (1992) minimizes the following quadratic form in $\phi$

$$
\left[Q_{T}(X)-Q_{N}(Y(\phi))\right]^{\prime} W_{T}\left[Q_{T}(X)-Q_{N}(Y(\phi))\right]
$$

Following Lee and Ingram (1992) we set

$$
W_{T}=\left[\left(1+\frac{T}{N}\right) \Lambda_{T}\right]^{-1}
$$

and use the Newey-West (1987) covariance estimator to construct an autocorrelation consistent estimator of the covariance matrix

$$
\Lambda=E\left\{\sum_{i=-\tau+1}^{\tau-1} \xi_{t+\tau} \xi_{t+\tau-i}^{\prime}\right\}
$$

where, $\xi_{t+\tau}=q\left(X_{t+\tau}\right)-\frac{1}{T} \sum q\left(X_{t+\tau}\right)$ and $\tau$ is the number of nonzero autocovariances in $q\left(X_{t}\right)$.

\footnotetext{
${ }^{5}$ In Section 5, we describe the method used to compute the equilibrium and simulate $\left\{Y_{j}(\phi), j \geq 1\right\}$.
} 
To implement this estimation procedure, we adopt the following additional assumptions. We assume that government investment, $i_{g, t}$, and government consumption, $c_{g, t}$ has conditional means that follow the same four state markov process that governs military investment. We also allow government consumption to vary with the current state of technology. This is done to capture peace-time fluctuations in government consumption. Our specification for $c_{g, t}$ is, therefore, given by

$$
c_{g, t}=g\left(s_{t}\right)+\zeta \log \left(z_{t}\right)
$$

where $g\left(s_{t}\right)$ is the component of government consumption that is correlated with military spending and $\zeta \log \left(z_{t}\right)$ is the component that is correlated with changes in technology.

In estimating the means of government investment and government consumption in each state, we condition on the estimated time series representation for military employment and the implied estimates of the current state. We also condition on $\beta=0.96$ which corresponds to a 4 percent annual discount rate and $\delta=0.0793$ which is the mean of investment over capital in the U.S. data for the sample we use.

Given these assumptions the parameter vector to be estimated is

$$
\phi=\left(\alpha, \gamma, p_{a}, p_{b}, \sigma, \rho, \theta, \zeta, \mu_{c_{g}, 2}, \mu_{c_{g}, 3}, \mu_{c_{g}, 4}\right)
$$

where $\alpha$ is a parameter used in specifying moving costs (i.e., $m\left(n_{t}, n_{t-1}\right)=\alpha\left(n_{t}-n_{t-1}\right)^{2}$ ), $\gamma$ is the weight on consumption in utility, $\sigma$ is the standard deviation of the innovation to the technology shock, $\rho$ determines the persistence of the technology shock, $p_{a}$ and $p_{b}$ are parameters used to specify the costs of entering the workforce (i.e., $p(n)=$ $\left.p_{b}\left\{\left(n-p_{a}\right)^{3}+\left|n-p_{a}\right|^{3}\right\}\right), \theta$ is the share of capital in production, $\zeta$ governs the covariance of government consumption with technology, and the $\mu$ 's are the conditional means for government investment and government consumption. Notice that several parameters have been excluded from $\phi$. The mean of $c_{g, t}$ in state 1 , the means of $i_{g, t}$ in the four states of the Markov chain for $s_{i}$, and the risk parameter, $\omega$, were all excluded from $\phi$. Because the model is not suited to explain movements during the Great Depression, we started the estimation in 1941 so state 1 does not occur. In our simulations, government consumption in state 1 was set equal to its unconditional average. We set the means of $i_{g, t}$ equal to zero and assumed that $k_{t}+k_{g, t}$ from the data was simply private capital stock. In this case, 
$i_{t}$ denotes total investment. This assumption has no effect on any of the other decision variables since the capital stocks are perfect substitutes. Finally, we set the risk aversion parameter equal to 1 , which implies logarithmic utility.

We identify the parameters in $\phi$ using the following moments

$$
q\left(X_{t}\right)=\left(\left(k_{t}+k_{g t}\right) / y_{t},\left(c_{g, t} / y_{t}\right) e_{t}, \log \left(z_{t}\right) \cdot \log \left(z_{t-1}\right), \epsilon_{t}^{2},\left(h_{t}\right) e_{t}, n_{t}, h_{t}^{2}, n_{t}^{2}, c_{p, t} / y_{t}\right)
$$

where $e_{t}$ is a $1 \times 4$ vector of ones and zeros with a one occurring in column $i$ if the military employment estimates imply that the current state is $i$.

Estimates of the parameters in $\phi$ are reported in Table 2 and are based on annual data for 1940-1985. Our estimate of the moving cost parameter $(\alpha=0.0496)$ is significantly smaller than that used by Kydland and Prescott [1991] who set $\alpha=0.5$. This is due in part to the differences in data frequency; we use annual observations while they use quarterly observations. The estimate for the utility parameter $\gamma$, which is the weight on consumption, is 0.223 . This parameter is identified by sample means of hours per worker, employment, and consumption. The estimates $p_{a}$ and $p_{b}$ imply the following utility cost function: $p(n)=1.03\left\{(n-0.54)^{3}+|n-0.54|^{3}\right\}$. Thus, if the fraction employed exceeds $54 \%$, there is a positive cost to increasing employment. The estimates of parameters governing the technology shock process are $\rho=0.81$ and $\sigma=0.026$. The share of capital in production is estimated to be $26.6 \%$. A key moment for identifying this parameter is the capital to output ratio. The parameter governing the correlation between the technology shock and government consumption is 0.20 , implying a positive correlation. The remaining parameters are the means of the component $g\left(s_{t}\right)$ of government consumption $c_{g, t}$. We estimate these for states 2,3 , and 4 . Notice that $\mu_{c_{g}, 2}$, the mean during World War II, is about three times $\mu_{c_{g}, 4}$, the mean during the Korean War, and about six times $\mu_{c_{g}, 3}$, the mean during the 'Cold War' period.

\section{Simulation Results}

In this section, we use the parameter estimates described in Section 4 to compute an equilibrium and to simulate time series. The results of the simulation are compared to U.S. data to see if the model can capture the wartime and postwar movements in employment and hours of work. 
To compute decision functions for consumption, hours of work, and employment, we use the procedure outlined in McGrattan (1993). ${ }^{6}$ To implement the procedure, we derive the first order conditions of the optimization problem in (11). This derivation yields two intertemporal constraints. We use these equations to compute the consumption function for an employed agent and the fraction employed. The consumption function for those not working can be found by substituting the $c_{1, t}$ and $n_{t}$ functions into the intratemporal constraint relating the marginal rates of substitution of the different types. Similarly, the hours function can be found by substituting the $c_{1, t}$ and $n_{t}$ functions into the intratemporal constraint relating the marginal utility of consumption and the marginal utility of leisure.

In Figures 2 and 3, we plot hours per worker and employment as functions of the capital stock (x-axis) and lagged employment with the state equal to either 1 (i.e. peacetime) or 2 (i.e. wartime) and the technology shock equal to 1.0. Notice how different the decision functions look for peacetime versus wartime. The functions for $s_{t}=1$ are steeper and higher than those for $s_{t}=2$. This implies a bigger response of hours per worker to shocks in wartime. Another key difference is the dependence on lagged employment in the two periods. In wartime, hours are set higher the higher was employment last period, but the differences are not large. In peacetime, last period's level of employment is an important factor for current hours. For example, the difference between the curves marked ' $0.4,1$ ' and ' $0.5,1$ ' is much larger than the curves marked ' $0.4,2$ ' and ' $0.5,2$ '. Figure 3 , which displays decision functions for employment, shows a result similar to the hours decisions. In particular, there is a large difference between the decisions in state 1 and the decisions in state 2 .

In Figures 4 and 5, we plot hours per worker and employment with moving costs set equal to zero. We plot these variables as functions of the capital stock ( $x$-axis) and the state (i.e., $s_{t}=1,2,3$, or 4 ) with the technology shock equal to 1.0. From Figure 4, we see that at high values of the capital stock, hours per worker is constant. At low values of the capital stock, hours per worker is no longer constant and varies with both the capital stock and the state of the fiscal shock. Higher expenditures imply higher hours of work per worker. In Figure 5, the choice of $p_{a}$ is clear. When employment is approximately equal to 0.53 there is a kink in the function. For low values of the capital stock and high

\footnotetext{
${ }^{6}$ A technical appendix is available upon request.
} 
values of government spending, the planner increases the hours per worker rather than the number employed because the costs of moving high- $\eta$ individuals are too high.

In Figure 6, we plot a simulation of government consumption (panel a) hours per worker (panel b), and employment (panel c). This simulation is done with parameters of Table 2, the realization of $s_{t}$ from the data, and $\epsilon_{t}=0, t \geq 0$. Notice that both labor inputs are predicted rise significantly during World War II. The model predicts that the hours per worker rose 15 percent between 1939 and 1943. In the U.S., this fraction rose 19 percent. Thus, the cost function has a large effect on the response of hours per worker. If the cost function is set equal to zero, the model predicts no change in hours per worker. Between 1939 and 1943, the fraction employed in the model rose 28 percent. In the data, the increase was only 12 percent.

Figure 6 also illustrates the effects of the fiscal shocks that are uncorrelated with technology. As expected, these shocks play an important role in World War II and the Korean War.

For the postwar period, our model predicts that the variability of employment exceeds that of hours per worker. The percent standard deviation for employment is 3.69 percent, and the ratio of the standard deviation of employment to the standard deviation of output is $0.76 .^{7}$ In the data, these figures are 2.02 percent and 0.66 . Thus, relative to output, the standard deviation of employment found in the model is in good agreement with the data. The model predicts a percent standard deviation for hours per worker equal to 1.42 percent. The ratio of the standard deviation of hours per worker to the standard deviation of output is 0.29 . These figures for the data are 1.29 and 0.41 , respectively. Thus, relative to the data, hours are still too smooth. However, these labor market predictions compare favorably to specifications considered by Kydland and Prescott [1991] and Cho and Cooley [1992]. Kydland and Prescott's specification with moving costs understates the relative variability of hours per worker to output by one-half. Cho and Cooley who consider preferences defined over employment and hours understate the same statistic by 46 percent.

We are currently in the process of examining the robustness of our results to alter-

7 Before computing the standard deviation, we take the logarithm of the series and remove the trend with the filter described in Prescott [1986]. The realizations of $s_{t}$ and $\epsilon_{t}$ are derived from the data. 
native specifications of the utility costs of entering the work force and the specification of government consumption. In the postwar period there is a significant autonomous component to government consumption that we have not yet incorporated into our analysis. 


\section{Data Appendix}

- private consumption $\left(c_{i}\right)$ - consumption of nondurables, services and durables 1987 constant dollars from NIPA table 1.2, per capita.

- private investment $\left(i_{t}\right)$ - fixed investment in 1987 constant dollars from NIPA table 1.2 , per capita.

- private capital $\left(k_{t}\right)$ - nonresidential plus residential net stock of capital in constant 1987 dollars from Fixed, Reproducible Tangible Wealth 1925-1988 tables A6 and A16, per capita.

- government capital $\left(k_{g, t}\right)$ - net stock of government owned and privately operated capital in constant 1987 dollars unpublished data from U.S. Dept. of Commerce, Bureau of Economic Analysis, per capita.

- government investment $\left(i_{g, t}\right)$ - constructed from government capital assuming a geometric depreciation rate reported in the text.

- government consumption $\left(c_{g, t}\right)$ - government purchases in constant 1987 dollars from NIPA table 1.2 net of government compensation of employees from NIPA table 3.8a and government investment, per capita.

- output $\left(y_{t}\right)$ - the sum of government consumption, government investment, private investment, and private consumption.

- working population- population 16 and over from U.S Historical Statistics from Colonial Times to 1970 , p.10 updated using pan17 from Citibase.

- military employment $\left(a_{t}\right)$ - Military personnel on active duty divided by working population from U.S Historical Statistics from Colonial Times to 1970 series y904 updated using various issues of Statistical Abstract of the United States.

- civilian employment $\left(n_{t}\right)$ - Persons engaged in production from NIPA table 6.8A divided by working population net of fraction employed in the military.

- hours per worker $\left(h_{t}\right)$ - average weekly hours for production workers in manufacturing from U.S. Historical Statistics from Colonial Times to 1970 series D803 from 1929-1946, then from 1947 to 1985 Citibase series lphrm, average weekly hours for production workers in manufacturing from the establishment survcy. This series was converted to a zero to one scale by multiplying by 48 (weeks worked per year) and then dividing by 4536 , the annual endowment of time. 


\section{References}

Braun, R. Anton and Ellen R. McGrattan. 1993. "The Macroeconomics of War and Peace," forthcoming in NBER Macroeconomics Annual.

Cho, Jang-Ok Cho and Thomas F. Cooley. 1992. "Employment and hours over the business cycle." Queens University mimeo.

Finn E. Kydland and Edward C. Prescott. 1991. "Hours and employment variation in business cycle theory." Economic Theory, 1:63-81.

Hamilton, James D. 1989. "A new approach to the economic analysis of nonstationary time series and the business cycle." Econometrica, 57:357-384.

Hamilton, James D. 1991. "State-space models." Handbook of Econometrics, Volume 4, eds. Robert Engle and Daniel McFadden, forthcoming.

Hansen, Gary D. 1985. "Indivisible labor and the business cycle," Journal of Monetary Economics, 16: 309-27.

Hansen, Gary D. 1985. “

Hornstein, Andreas and Prescott, Edward C. 1993. "The plant and the firm in general equilibrium theory." forthcoming in General Equilibrium and Growth: The Legacy of Lionel McKenzie, eds. Robert Becker, Michele Boldrin, Ronald Jones, and William Thomson. New York: Academic Press.

McGrattan, Ellen R. 1993. "Solving the stochastic growth model with a finite element method." Federal Reserve Bank of Minneapolis, working paper \#514.

Prescott, Edward C. and Townsend, Robert M. 1984. "Pareto optima and competitive equilibria with adverse selection and moral hazard." Econometrica, 52: 21-45. 


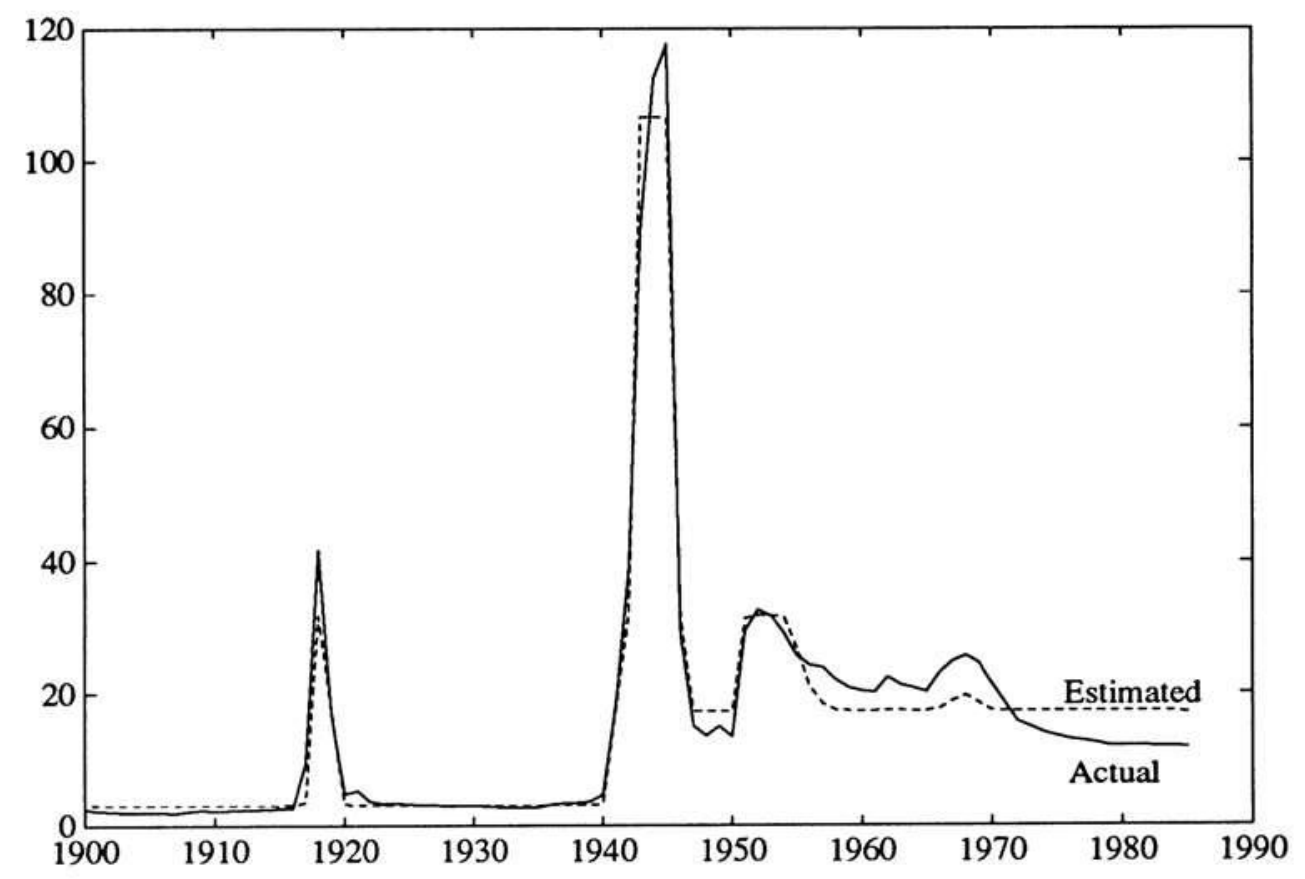

Figure 1. Estimates of 4-state Markov process for military employment. 


\begin{tabular}{||l|l|l|l|l|l|l||}
\hline \hline \multicolumn{7}{|c|}{ Table 1. MIE estimates of military-employment } \\
Markov process $1900-1985 \star$
\end{tabular}

*Standard errors are reported in parentheses. The $(2,1),(1,2),(2,3)$ and $(1,4)$ elements of $\pi$ were constrained to be zero after unconstrained estimation put them on the corner. Standard errors are not reported for the fourth row. These estimates are implied by the other three rows. 


\begin{tabular}{|c|c|}
\hline Parameters & Estimates \\
\hline$\alpha$ (moving costs) & 0.0496 \\
\hline$\gamma$ (consumption utility weight) & 0.223 \\
\hline$\rho_{a}$ (utility cost startup) & 0.540 \\
\hline$\rho_{b}$ (utility cost curvature) & 1.031 \\
\hline $\begin{aligned} \sigma_{\varepsilon} & \text { (technology shock } \\
& \text { variability) }\end{aligned}$ & 0.0259 \\
\hline $\begin{array}{l}\rho \text { (technology shock } \\
\text { persistence) }\end{array}$ & 0.810 \\
\hline$\theta$ (capital share) & 0.266 \\
\hline $\begin{array}{ll}\mu_{c g, 2} \text { (conditional means } \\
\mu_{c g, 3} \text { of government } \\
\mu_{c g, 4} \text { consumption) }\end{array}$ & $\begin{array}{l}0.115 \\
0.0210 \\
0.0400\end{array}$ \\
\hline $\begin{array}{l}\zeta \text { (covariance of technology and } \\
\text { government consumption) }\end{array}$ & 0.200 \\
\hline
\end{tabular}




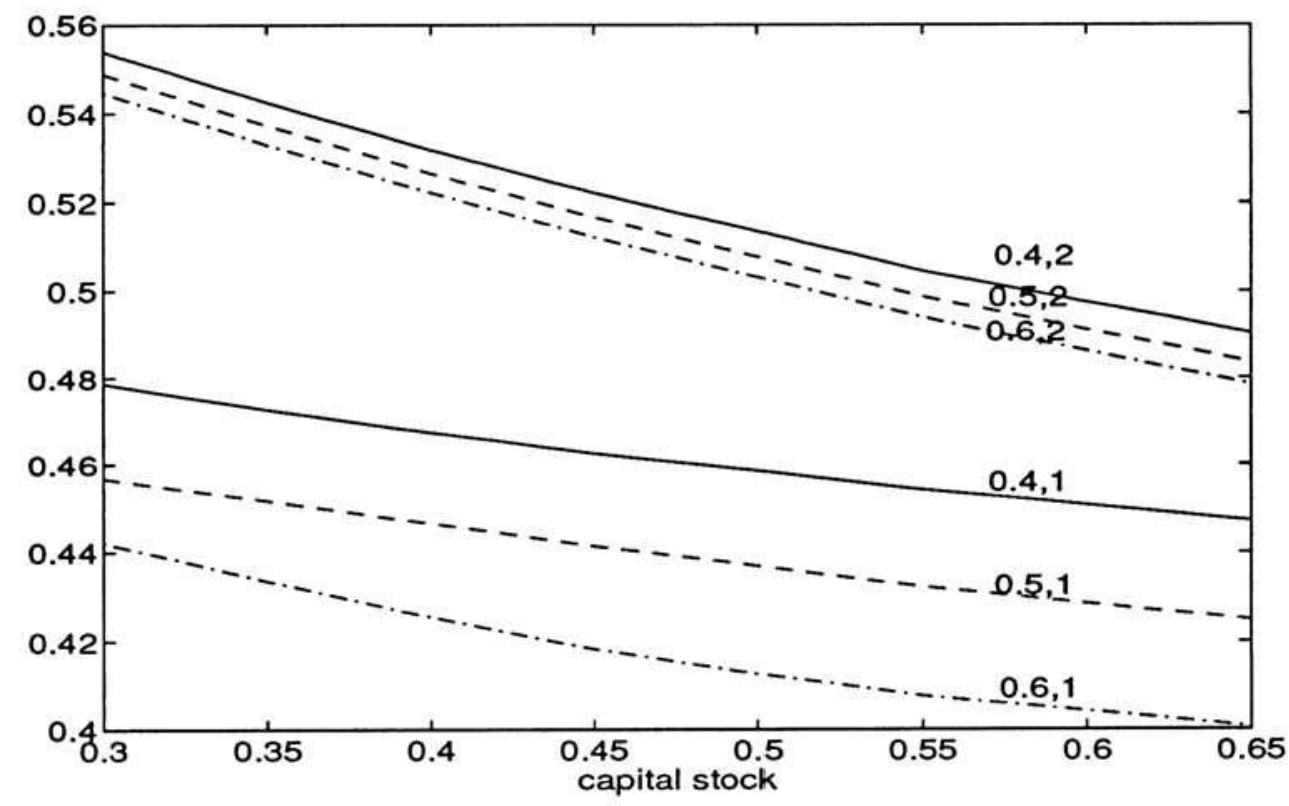

Figure 2. Hours per civilian worker decision functions with $z=1$. (Values for last period employment and the state $s_{t}$ are given for each curve.)

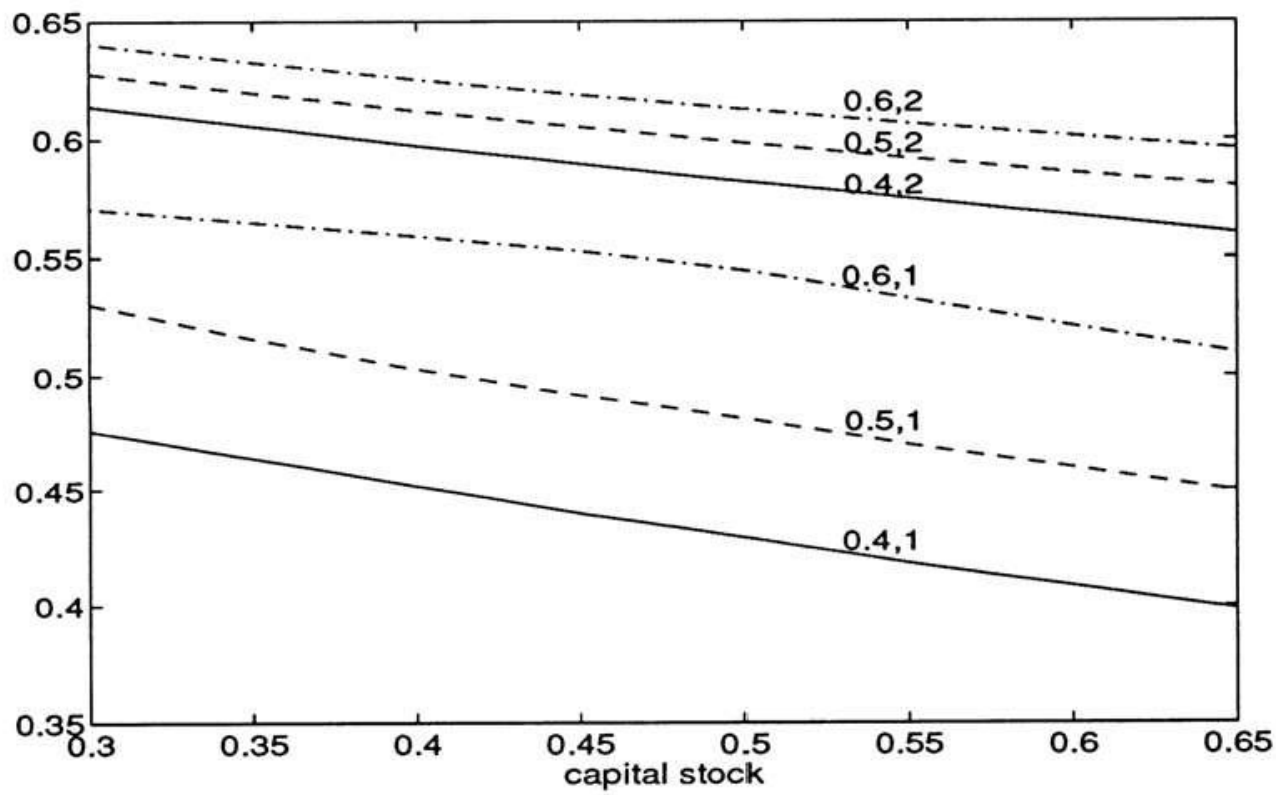

Figure 3. Civilian employment decision functions with $z=1$. (Values for last period employment and the state $s_{t}$ are given for each curve.) 


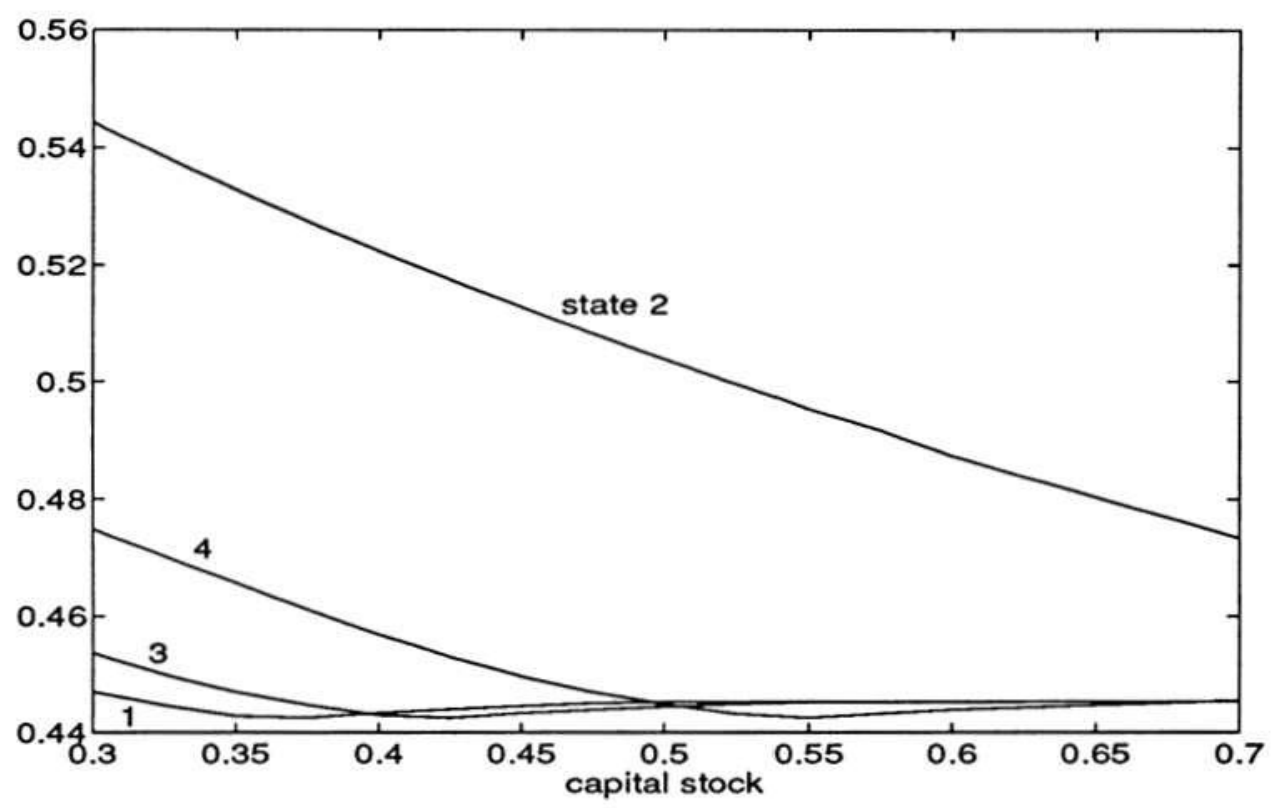

Figure 4. Hours per civilian worker decision functions with no moving costs, $\alpha=0$, and $z=1$. The four curves are decisions for the four states, $s_{t}$.

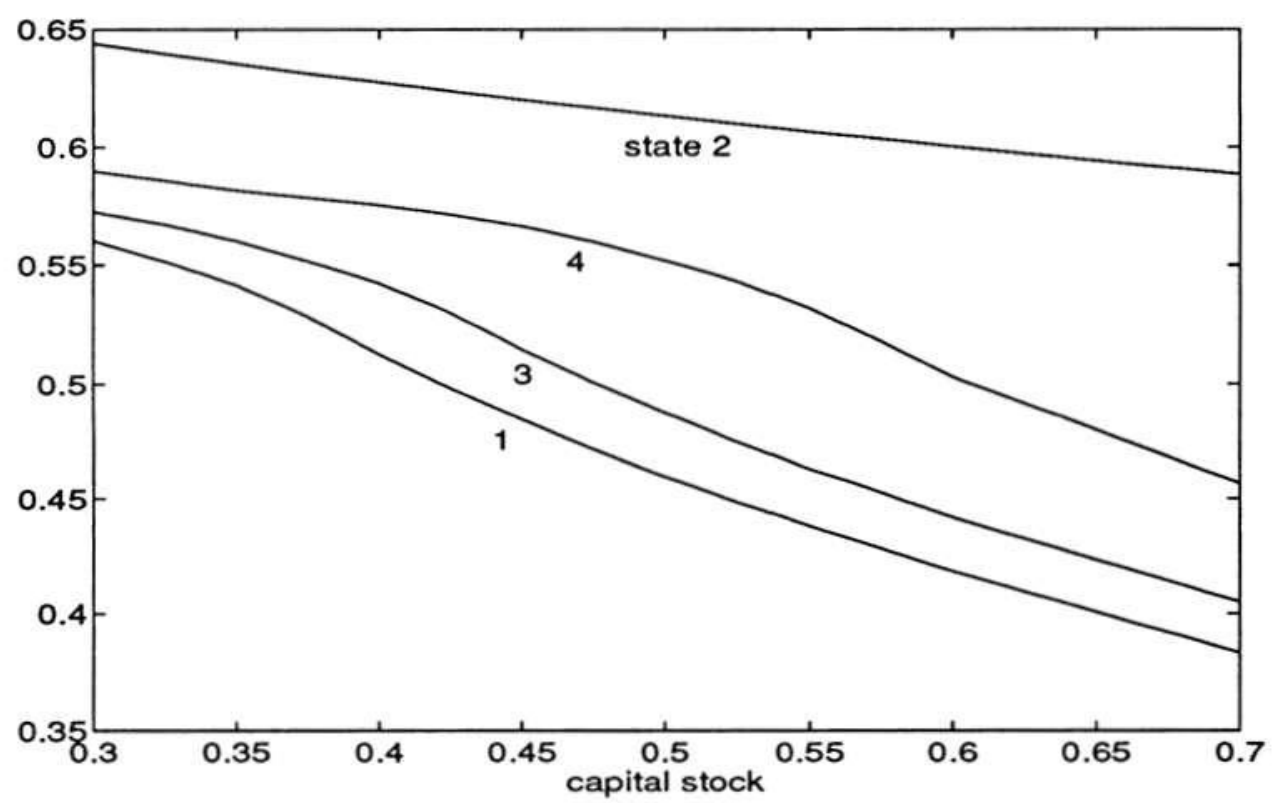

Figure 5. Civilian employment decision functions with no moving costs, $\alpha=0$, and $z=1$. The four curves are decisions for the four states, $s_{t}$. 

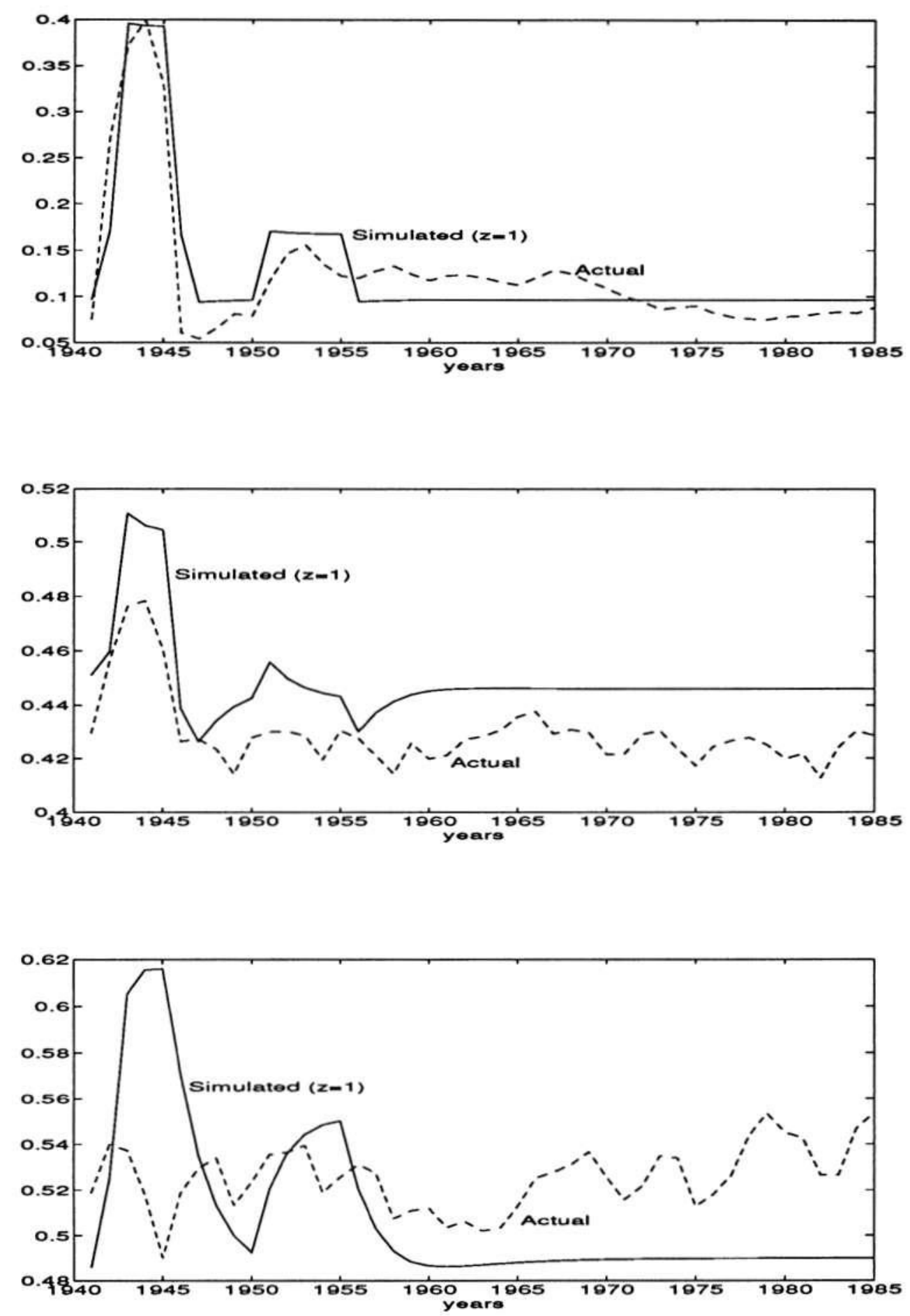

Figure 6. A simulation of government consumption (panel a), hours per worker (panel b), and per-capita employment (panel c) with $z_{t}=1, t \geq 0$. 